\title{
NOTAS SOBRE MAGIA Y HEREJÍA EN EL JOSÉ DE LAS MUJERES. CALDERÓN TIENTA AL DEMONIO
}

Fdward M. Wison se ocupó en 1973 de los reparos teológicos que a algunos versos de la comedia El José de las mujeres les puso el inquisidor y censor de escena D. Juan de Rueda y Cuebas, y que sólo pueden ser entendidos como una acusación de herejía hecha contra Calderón. Las brevísimas líneas que siguen no pretenden ser sino una apostilla a esta cuestión. El pasaje que dio lugar a la intervención inquisitorial se sitúa al final de la jornada primera de la pieza, momento en el que los galanes Cesarino y Aurelio riñen con espadas en un lance provocado por la disputa de los favores de la dama Eugenia, y en el que el primero hiere y mata al segundo. Calderón, dispuesto a dificultar la conversión al cristianismo de la dama pagana, se sirve del cadáver del galán haciendo que el Demonio se introduzca en él y actúe valiéndose de la confusión que crea a partir de entonces un endemoniado Aurelio.

Sacan las espadas y cae Aurelio muerto a la parte del tablado, que pueda abrirse un escotillón a sus espaldas, y Eugenia cae desmayada al otro lado, descúbrese el Demonio en lo alto, desde donde ha de caer lo más veloz que pueda a esconderse por el escotillón, y levántase Aurelio assombrado al mismo tiempo, y vase.

${ }^{1}$ M. WlLSON, "Inquisitors as censors im Seventeenth-century Spain", Expression, communication and experience in literature and language. Proceedings of the XII Congress of the International Federation for Modern Languages and Literatures, ed. R. G. Popperwell, The Modern Humanities Research Association, Cambridge, 1973, pp. 38-56, reimpreso como "Inquisición y censura en la España del siglo xvil", Entre las jarchas y Cernuda. Constantes y variables en la poesia espanola, Ariel, Barcelona, 1977, pp. 245-272. E. M. WlLson ya había anotado esta censura previa a la representación de la pieza en "Calderón and the stage-censor in the Seventeenth Century. A provisional study", Symposium, 15 (1961), pp. 174-175. 


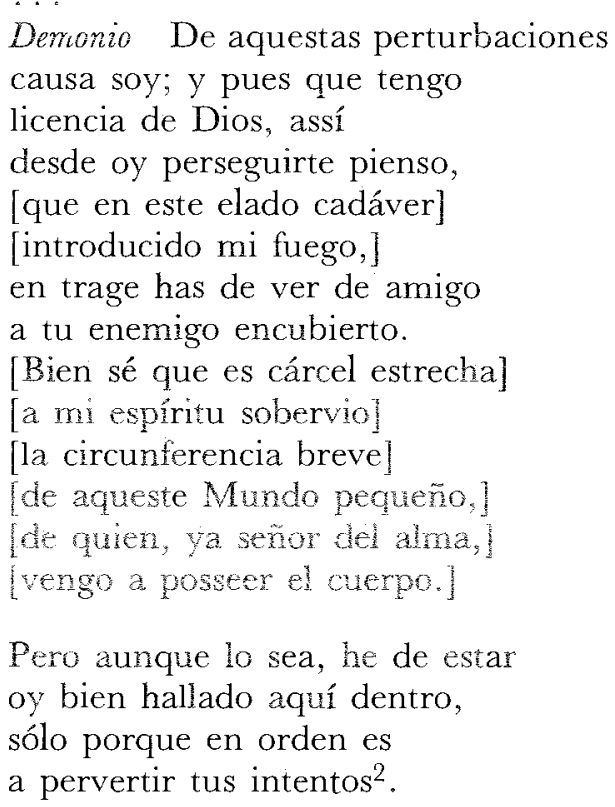

Sobre el texto de una copia manuscrita de la comedia, de 1669 (ms. 16.548 de la B.N.M.), el maestro Don Juan de Rueda y Cuebas estampó el 18 de noviembre de 1670 su censura escénica:

Que se obserbe lo borrado y que el demonio no entre en el cadáber por ser Erético y Contra el viejo y nuevo testamentos y contra la dotrina de los Stos. Padres y Concilios en especial Contra guatro Concilios generales Como Consta de la coreción echa en la Ciomedia que se trujo...

La escena, sumamente compleja escenográficamente ${ }^{3}$, pues sólo en manos de volatineros saldría airosa la combinación de

2 Transcribo el texto de la Sexta Parte de comedias del célebre poeta español Don Pedro Calderón de la Barca, Juan Sanz, Madrid, 1715 (B.N.M. signatura T 1845). Señalamos entre corchetes los versos que fueron objeto de la censura inquisitorial.

${ }^{3}$ Calderón viene con ella a abonar un terreno, el de la magia anamorfótica y perspectiva, largamente roturado a lo largo del Xvil. Atanasius Kircher, Ars magna lucis et umbrae in decem libros digesta (1645) y el jesuita Gaspar Schott, Magia universalis Naturae et Artis, sive recondita naiuralium et artificialium rerum scientia (1676) se enzarzaron en el estudio del trampantojo barroco, al que en cierto modo contribuye Calderón con el diseño tramoyístico de la escena de la posesión de Aurelio. Véase Julio Caro Baroja, Teatro popular y magia, Rev. de Occidente, Madrid, 1974, pp. 22-29. 
escotillón y pescante, presenta un luminoso ejemplo de posesión demoníaca. Pese a que el Padre Diego de Calleja pergeñará una añagaza semejante para su comedia El Fénix de España, San Francisco de Borja (1671), el caso es insólito en el teatro español aurisecular, y no debiera soslayarse si se pretenden entender las relaciones calderonianas con la demonología del seiscientos. Vale la pena volver tras los pasos de Wilson, pues lejos de ser ésta una cuestión baladí, un caprichoso reparo inquisitorial, nos las habemos con una escena que introduce a Calderón en el espinoso terreno de la ortodoxia católica del Xvm, y que lleva detrás una fecunda controversia sobre la posesión demoníaca que parte de San Agustín y de Santo Tomás, y de la que Calderón no se mantuxo disnd.

Quaife ha insistido en el hecho de que la usurpación demoníaca de un cuerpo humano fue un aspecto primordial del diabolismo en el siglo Xvir, como lo prueba el Discours des sorciers que publicó sobre este particular el magistrado Henri Boguet, en 1602, o el tratado De Natura Daemonum (1596) que sacó a la luz el demonólogo napolitano Juan Lorenzo Ananias, y que posiblemente llegara a conocer Calderón, y para Caro Baroja "no cabe duda de que a fines del siglo XVI y comienzos del XVII hubo una verdadera obsesión por la presencia física del Demonio en el mundo" 5 . Pero conviene dejar a un lado la predisposición que pudiera tener el espectador barroco de la comedia al advertir la fuerza que Dios le permite ostentar al Demonio, y centrarse en la bizantina cuestión de la ortodoxia de llevar a escena una posesión demoníaca, esto es, conviene discemir el trigo teológico de la paja dramática. Coincidimos con Wilson ${ }^{6}$ a la hora de considerar irrelevante para el espectador si el Demonio resultaba estar realmente encarnado en el cadáver del galán Aurelio, o si por el

${ }^{4}$ G. R. Quarpe, Magia y maleficio. Las brujas y el fanatismo religioso, Crítica, Barcelona, 1989, p. 73 et passim. En T. K. Oesterreich, Possession: Demoniacal and other among primitive races in Antiquity, the Middle Ages and Modern Times, University Books, Secaucus, NJ, 1966. pp. 212-264, encontraxá el lector ejemplos aducidos en favor de la preponderancia de la posesión en los debates que suscitó la demonología barroca. Véase también $\mathrm{K}$. M. BRIcas, "Some Seventeenth Century books of magic", Folklore, 64 (1953), 445-462; JuLES Michelet, "Triunfa Satanás en el siglo XviI", La bruja, Labor, Barcelona, 1984, pp. 249-257. p. 96.

${ }^{5}$ Julio Caro Baroja, Magia y brujería, Txertoa, San Sebastián, 1987,

${ }^{6}$ E. M. WILson, "Inquisición y censura en la España del siglo XVI", ed. cit., p. 269. 
contrario aquél tomaba la forma de un corpóreo fantasma que sustituiría a éste. A los ojos de quienes acudiesen al corral, esta cuestión no pasa de ser una nugae que en nada empaña una de las escenas más arriesgadas del teatro de su tiempo, pero sí reviste indudable interés estudiar hasta qué punto los reparos del censor Rueda y Cuebas se vieron arropados por autoridades de las que se nos hace muy difícil pensar que Calderón, antiguo alumno del Colegio Imperial de Madrid y dotado de una formación escolástica impecable, no tuviese conocimiento y, en consecuencia, cumple tratar de averiguar si el dramaturgo incurrió a sabiendas en la herejía, tal vez por el deseo de llevar hasta el límite la poética barroca de la admiratio.

Las conclusiones de Wilson en este punto son demasiado confusas $y$, no exculpando a Calderón, tampoco le recrimina la audacia teológica del lance. Esgrime a vuela pluma las interpretaciones que Santo Tomás y Ciruelo dan del fenómeno de la posesión, negando cualquier posibilidad de que el Demonio pueda resucitar el cadáver de un hombre, y parece decantarse por la idea de que Calderón siguió en este punto las argumentaciones del doctor Gaspar Navarro en su Tribunal de superstición ladina (Huesca, 1631), que le permitían presentar la escena sin riesgo aparente de heterodoxia, a través de lo que se nos antoja que es una trampa sofista: a juicio del canónigo aragonés, el Demonio puede introducirse en un cadáver y llevarlo de un lado a otro, hacerle hablar con su propia lengua y moverse. Pero los actos humanos proceden de un principio intrínseco-vital que emana del alma y da vida al cuerpo, y en un cuerpo sin vida no existe tal principio, por lo que los movimientos y las facultades que el Demonio obtuviese en el cuerpo de Aurelio serían en cualquier caso extrínsecos, pues no parten de la voluntad del alma del difunto, sino de la propia voluntad del demonio. Sin embargo, como anota el propio Wilson "¿quién puede afirmar si los actos del resucitado Aurelio estaban descritos según un principio extrínseco o uno intrínseco-vital?"7. Esta disyuntiva no modifica las circunstancias de la puesta en escena de la comedia, pero sí facilita que la sombra de la herejía se cierna sobre la escena concebida por el dramaturgo, que parece que pudo seguir el ejemplo de una posesión en la que el Demonio alcanzó a usurpar por un año el cadáver de un hombre como si éste anduviese dotado de alma, ejemplo aducido por el doctor Navarro apoyándose

${ }^{7}$ Ibid., p. 267. 
en la dudosa autoridad de Caesarius Heisterbachensis, cuyo Illustrium Miraculorum \& Historiarum Mirabilium (Amberes, 1605) fue precisamente prohibido por la Inquisición en el Index Librorum Prohibitorum de 1667, donec prodeat expurgatio.

Los versos de la comedia son suficientemente explícitos:

Bien sé que es cárcel estrecha
a mi espíritu sobervio
la circunferencia breve
de aqueste Mundo pequeño,
de quien, ya señor del alma,
vengo a posseer el cuerpo,

y la censura de Rueda y Cuebas no deja lugar a la duda respccto a su alcjamiento de los cánones emanados de las Sagradas Escrituras. En efecto, Salmo 71 [72],18 y Salmo 135 [136],4 proclaman que sólo Jehová Dios, Dios de Israel, es capaz de hacer maravillas, y no le es dado al Demonio alterar el orden de la Naturaleza creada por Dios, y menos aún - y ésta es cuestión medular - ejercer control alguno sobre el alma humana. La Iglesia contrarreformista a la que se debía Calderón edificó el templo de la ortodoxia, en materia de demonología, sobre los cimientos que dispuso el tomismo, y Santo Tomás negó la potestad del Demonio para resucitar el cadáver de un hombre o para engendrar vida a par̂tir de él mediante una nueva enclisis del alima con el cuerpo (Summa Theologica, Parte I, Q. 114, Art. 4: "cum enim ipse possit formare corpus ex aere cuiuscumque formae et figurae potest eadem ratione circumponere cuicumque rei corporeae quamcumque formam corpoream" ). Recuerda Ángel I. Cilvet ${ }^{8}$ que, en cambio, sí acepta que el Demonio pueda formar fantasmas para la vista de los que se alimenta la imaginación (Summa Tehologica, Parte I, Q. 111, Art. 3), si bien el desarrollo dramático de El José de las mujeres no permite interpretar la actuación del endemoniado Aurelio sino como posesión demoníaca, esto es,

8 Ángel L. Cilveti, El demonio en el teatro de Calderón, Albatros, Valencia, 1977, p. 156. A. A. PARker, "The devil in the drama of Calderón", en Critical essays on the theatre of Calderón, ed. B. W. Wardropper, New York University Press, New York, 1965, p. 20, puesta la mirada en El mágico prodigioso, recuerda los límites que el tomismo le puso al poder del demonio en relación con el modo en que Calderón lo maneja en su obra dramática. Cf. J. DE Tonquḱdec, S. J., "Some aspects of Satan's activity in this world", Satan. Études Carmelitaines, 27 (1948), 38-44. 
como una presencia corpórea en la escena que resulta doblemente herética, por cuanto tiraniza el alma de Aurelio sometiéndola a los designios del Demonio. Alexander A. Parker ya había apuntado que

the necessity of personifying the Devil in anthropomorphic form makes him confront his human victim as man to man, with the power to excercise a direct external influence on his will ${ }^{9}$,

y no otra cosa es lo que sucede en las dos últimas jomadas de El José de las mujeres, con el Demonio haciéndose pasar por Aurelio para confundir a Eugenia y apartarla del camino del cristianismo por el que pretende levarla su antagonista Eleno, concebido como la Gracia encarnada. Pero importa advertir ahora cómo Calderón, por cumplir con las expectativas dramáticas que él mismo se impuso en la pieza, acabó descuidando los preceptos dictados por la Iglesia, aun a pesar de la cautela con la que puso en boca del Demonio una frase que habría de actuar de salvoconducto ante el Santo Oficio, "y pues que tengo licencia de Dios", conjuntamente con los versos que cierran la posesión demoníaca de Aurelio al final de la jornada tercera de la comedia, y que perfilan la subordinación del poder demoníaco al poder de $\operatorname{Dios}^{10}$ :

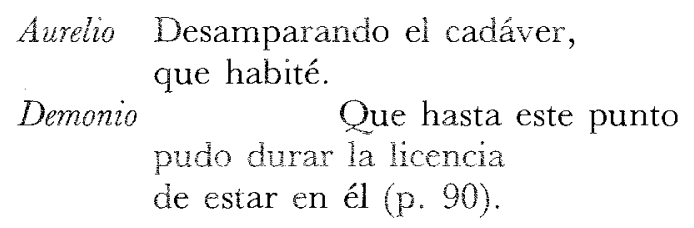

Es bien conocida la forma alegórica en que Calderón maneja la figura demoníaca en sus autos ${ }^{11}$, y no lo es menos la función del Demonio como valiosa pieza en el ajedrez escolástico en que el dramaturgo convierte varias de sus comedias religiosas, muy especialmente El purgatorio de San Patricio (1636), El mágico prodi-

${ }^{9}$ A. A. PARker, art. cit., pp. 4-5.

${ }^{10} \mathrm{Cf}$. Ambroise Paré, Des Monstres et prodiges (Gabriel Buon, Paris, 1585), ed. I. Malaxecheverría, Siruela, Madrid, 1993, "Sobre aquellos que están poseídos de los demonios, que hablan en diferentes partes de sus cuerpos", pp. 79-80: "los espíritus malignos son los ejecutores y verdugos de la alta justicia de Dios, y nada hacen si no es con su consentimiento", p. 80.

11 Ángel L. Cilveti, "Demonio-Eucaristía" y "La alegoría", op. cit., pp. 67-94 y $95-129$. 
gioso (1637) y Los dos amantes del Cielo. También en El José de las mujeres se construye el entramado propio de una disputatio en la que politeísmo y cristianismo se contraponen a través de un juego de silogismos, pero Calderón lleva demasiado lejos aquí la imagen del Demonio, presentando una escena de posesión que, a la luz de los tratadistas que estuvieron a su alcance, no sólo se ganó merecidamente la reprobación de 1670 , sino que fue concebida sin atender a las argumentaciones de los tratados de demonología.

En el capítulo 58 de su De Occulta Philosophia, sacada a la luz por Hetorpius en Colonia, en 1533 y no sin habérselas antes con el inquisidor Conrad d'Ulm, Enrico Conelio Agrippa ${ }^{j 2}$ esgrime las autoridades de Plinio, de Apuleyo y de Mario de Damasco para verificar la posibilidad de la reanimación y resurrección de los muertos, pero hace hincapié en el hecho de que sólo se trata en realidad de casos naturales de éxtasis, síncopes, catalepsias y otras formas de criptobiosis forzadas por bebedizos y por efectos de carácter psicosomático. Agrippa se aleja así de cualquier interpretación demoníaca de las mencionadas alteraciones del estado de un cuerpo, del mismo modo que uno de los tratadistas más interesantes del xvi, Fray Martín de Castañega, advierte en su Tratado muy soili y bien fundado de las supersticiones y hechicerias (Miguel de Eguia, Logroño, 1529) la amenaza de herejía para quienes proclamen la atribución al Demonio de algunos fenómenos que la opinión popular relacionaba entonces con la posesión y el poder demoníaco sobre la muerte.

Wilson ${ }^{13}$ justifica el cadáver diabólicamente animado de Aurelio y, en consecuencia, los engañosos versos que pone en su boca hasta que el Maligno abandona el cuerpo, recordando que Ciruelo había afirmado que el Demonio podía mostrarse en forma humana e introducirse en el cuerpo de un hombre muerto y hacerle hablar, lo que podría tratarse sólo de "una especie de diabólica ventriloquia" 14 . Pero aceptar la certeza de tales añagazas no disminuye el carácter herético de la escena concebida por el dramaturgo, máxime si tenemos en cuenta las argumentaciones del propio maestro Pedro Ciruelo en su Reprouación de las supersiciones y hechizerías (Pedro de Castro, Salamanca, 1538), tra-

12 Enrico Cornelio Agrippa, Filosofía oculta, ed. B. Pastor de Arocena, Alianza, Madrid, 1992, pp. 226-231.

${ }^{13}$ E. M. WILson, art. cit., pp. 266-267.

${ }^{14}$ Bbid., p. 266. 
tado reimpreso en 1540, 1541, 1547 (tres ediciones), 1548, 1551, 1556 y 1628, edición que debió de manejar Calderón:

Y quiso el Señor avezarnos a huyr de oyr las palabras del demonio, avnque nos parezca que dice verdades, porque es cosa muy nefaria, o mala que donde tenemos la santa escritura y la dotrina de la yglesia cathólica, queramos aprender del diablo. $\mathrm{Y}$ ansí parece que estos santos dotores nos avisan, que no deuemos oyr las palabras del demonio avnque siempre dixese verdad quanto más que en sus hablas siempre entre las verdades mezcla mentiras. $Y$ es cosa muy peligrosa a los christianos oyr las razones que el demonio dize por la boca del hombre endemoniado ${ }^{15}$.

A la luz de las palabras de Ciruelo, Calderón jugo en la ficción dramática de su comedia con una circunstanciá de todo punto heterodoxa, aventurándose a dejar a su auditorio en una posición comprometida en relación con la Iglesia. $Y$, claro está, el censor Rueda y Cuebas no tenía por qué estar dispuesto a discernir entre la realidad herética y la ilusión dramática, y no lo estuvo. Ciruelo se ocupa más adelante de la posesión, y desacredita cualquier artimaña que pudiese emprender el Demonio con el propósito de devolverle la vida a un hombre:

Digo que todos los buenos cristianos tengan por cierta sentencia, que nunca ánima de persona defuncta torna a se enuestir en cuerpo de persona biua, porque avnque alguna vez y muy tarde dios permita. que alguna ánima de la otra vida venga acá a se aparecer a los biuos, aquello no es entrando en cuerpo de alguná persona de esta vida, sino tomando cuerpo phantástico del ayre...16. Luego

15 Pedro Ciruelo, Reprouación de las supersticiones y hechizerías, ed. A. V. Ebersole, Albatros, Valencia, 1978, p. 114. Las cursivas son nuestras.

${ }^{16}$ También El Tostado niega la capacidad del demonio para asumir cualquier cuerpo humano si no es en forma de fantasmagoría, supuesto que se contradice con la actuación del endemoniado Aurelio hasta el final de la comedia. Cf. Alonso de Madrigal, Operum, Coloniae Agripinae, sumpt. J. Gymnici \& A. Hierati, 1613, II, p. 76 F: "digamos, pues, que cuando los ángeles buenos o malos se aparecen en cuerpos que han asumido, lo que realmente asumen es cierto globo o esfera de aire...". Niega asimismo la corporeización del demonio en la posesión de un cadáver PIERRe Le LoYer, Discours et histoires des spectres, visions et apparitions des esprits, anges, demons, et ames, se monstrans visibles aux hommes (Nicolas Bvon, Paris, 1605). Ambos testimonios acentúan la certeza de que, tal como está concebida la escena del endemoniamiento de Aurelio, Calderón se halla en falso con respecto a los cánones de la ortodoxia católica. 
el espíritu que habla en el que está endemoniado, o espiritado no es alma de hombre, antes es verdaderamente diablo engañador. Y si dize que es alma, él miente como maldito falso traydor ${ }^{17}$.

Al concebir la escena como un acto explícito de posesión demoníaca, y no como una suerte de fantasmagoría, Calderón infringe demasiados cánones de la ortodoxia. Mair ${ }^{18}$ se ocupó de agavillar los puntos heréticos de la posesión tal y como era concebida por los tratadistas barrocos, algunos de los cuales llegaron a alcanzar una difusión suficientemente notable como para no considerar descabellada la idea de que pudiera haberlos consultado Calderón. Es el caso de Hieronymus Mengus, cuyo Flagellum daemonum, exorcismos teribies, potentissinos, et effucucs (Lyon, 1608) se convirtió en moneda de uso corriente, superadas ya las controversias acerca del Malleus Maleficarum, en el erudito mercado de la demonología del xvii. Mengus rechaza asimismo cualquier idea de ortodoxia en las maquinaciones demoníacas con cuerpos sin vida y en la práctica de la posesión, y le sigue en este particular Henningus Grosius en su Magica de spectris et apparitionibus spiritum. De Vaticiniis, Divinationibus, impresa por Franciscus Hackium en Lyon, en 1656.

Un tratadista fundamental para lo que nos ocupa es el jesuita Martín Antonio del Río y López de Villanueva, cuyas Disquisitionum Magicarum (Gerardo Rivio, Lovaina, 1599-1600), reeditadas en 1612, conoció Calderón. Del Río afirma que “"a veces asumen los demonios algún cadáver de hombre o bestia, y lo mueven e impulsan con movimiento no vital, sino sólo local, lo mismo que pueden impulsar el aire... Pero negamos los argumentos que aducen de los cadáveres asumidos por espíritu maligno"19. Estas palabras, arropadas por una erudición incuestionable y por argumentaciones que esgrimen la autoridad de la Biblia y de los Santos Padres, y avaladas por las Relecciones theológicas (J. Boyer, Lyon, 1557) de fray Francisco de Vitoria, ponen en entredicho la ortodoxia de la escena concebida por Calderón para salvaguardar el equilibrio de fuerzas en la disputatio entre Eleno, la Gracia divina, y el Demomio en relación con las dudas de fe de Santa

${ }^{17}$ Pedro Ciruelo, op. cit., pp. 114-115.

${ }^{18}$ L. MAIR, "Witchcraft, spirit possession and heresy", Folklore, 91 (1980), 228-238. Véase Julio Caro Baroja, “Brujería y posesión demoníaca", Las brujas y su mundo, Alianza, Madrid, 1966, pp. 173-183.

${ }^{19}$ Martín del Río, La magia demoníaca, ed. J. Moya, Hiperión, Madrid, 1991, t. 1 , pp. 568-569. 
Eugenia. Más delante, después de aseverar que "para resucitar al hombre tiene el demonio muy poco o ningún poder. No puede hacer que un hombre resucite de entre los muertos; o lo que es lo mismo, no puede hacer que el alma humana se reintroduzca en su cuerpo y le dé forma y vida"20, Del Río confirma que

el demonio no puede informar el cuerpo por sí mismo, por ser una sustancia perfecta y completa a la que repugna formar parte de cualquier otra sustancia.. Podría el demonio, si Dios lo permitiese, obligar a un ánima condenada a meterse en un cuerpo para moverlo y hacer demostración de algunas operaciones en el mismo... También puede meterse en un cadáver y manejarlo, moverlo, y por algún tiempo realizar las denás operaciones por las que parezca que vive?

Pero Calderón no perfila el endemoniamiento de Aurelio como una añagaza demoniaca que controle el cadáver del galán haciéndolo funcionar en escena a modo de autómata, sino que establece una suerte de metempsícosis por la que el Demonio le insufla nueva vida dotándolo de alma. Y por otro lado, la escenografía de la pieza concibe la posesión del cuerpo de Aurelio conforme a formas y procedimientos contrarios a los que los demonólogos y tratadistas del XVI y del xvI venían avalando como canónicos y verosímiles. Calderón no quiso familiarizarse con la letra pequeña de los tratados que tuvo a su alcance, ollevó demasiado lejos la subordinación de la ortodoxia a la eficacia dramática de la escena, adentrándose de este modo en el bosque de la herejía y justificando los reparos teológicos que Rueda $y$ Cuebas, sin necesidad de erigirse en censor más estricto de la cuenta, anotó en el texto de la copia manuscrita de 1669. Tal vez pudiéramos aducir, en descargo del dramaturgo, ese talante escéptico para los encantamientos que había mostrado cuando compuso La dama duende, y que empezaba a ser común entre los hombres de su tiempo. 